\title{
Role of a clinical prediction score in a chronic thromboembolic pulmonary hypertension rule-out strategy
}

\author{
To the Editor:
}

Chronic thromboembolic pulmonary hypertension (CTEPH) is a rare and serious complication after pulmonary embolism (PE). Its incidence in the general population is around 3-30 cases per million. The incidence of CTEPH after acute PE ranges between 0.1 and $8.8 \%$ [1-5]. In a meta-analysis including 4047 PE patients, the incidence of CTEPH was $2.8 \%$ (95\% CI 1.5-4.1) in "PE survivors" without major comorbidities [6]. In studies not using objective diagnostic criteria to diagnose CTEPH, the pooled incidence was $6.3 \%$ (95\% CI 4.1-8.4) [6].

To diagnose CTEPH, a number of tests are required. Transthoracic echocardiography (TTE) should always be performed when CTEPH is suspected, but is not enough to support a treatment decision. It is mandatory to demonstrate the combination of precapillary pulmonary hypertension (defined by mean pulmonary arterial pressure (PAP) levels $\geqslant 25 \mathrm{mmHg}$ at rest) on right heart catheterisation and mismatched perfusion defects on lung scan. All patients also need a multidetector computed tomography angiography, magnetic resonance imaging or conventional pulmonary angiography to look for specific signs such as ring-like stenosis, webs/slits and/or chronic total occlusions (pouch lesions or tapered lesions) [7]. The prognosis of patients with CTEPH without treatment is poor [8], but early detection and pulmonary endarterectomy (PEA) may improve outcomes considerably. In fact, the time elapsed between the last PE episode and PEA influences the mortality rate [9]. However, a significant number of patients, presumably $40 \%$, develop CTEPH in the absence of prior acute PE [10,11].

TTE is considered the first test in the diagnostic algorithm for CTEPH, but routine TTE in all patients with PE is not cost-effective, given its low diagnostic yield for CTEPH of around 25\% 6-12 months after an acute episode of PE $[12,13]$. Consequently, current guidelines from the European Society of Cardiology/European Respiratory Society recommend that TTE is only considered in patients with exercise/persistent dyspnoea several weeks after PE [7, 14]. The most common symptom of CTEPH initially is progressive dyspnoea on exercise, although some patients with PE may transiently experience some improvement in symptoms. Therefore, early identification of CTEPH soon after the PE is difficult.

A simple and noninvasive tool that could be used as a routine assessment in patients with acute PE might help to discriminate those patients that could safely avoid further diagnostic tests. Recently, a clinical prediction score for CTEPH was derived from three large prospective cohorts including 772 patients with acute PE [15]. The authors built a clinical prediction score assigning points to six clinical variables: unprovoked PE, known hypothyroidism, symptom onset $>2$ weeks before PE diagnosis, right ventricular dysfunction on computed tomography or TTE, known diabetes mellitus, and thrombolytic therapy or embolectomy. They considered the diagnosis very unlikely in patients scoring $\leqslant 6$ points. The sensitivity of the score obtained with this threshold was $91 \%$ (95\% CI 70-98\%).

We tried to externally validate this score in a CTEPH rule-out strategy in 2256 patients with acute $\mathrm{PE}$ included in the RIETE registry. Patients with history of heart failure or chronic pulmonary disease were not considered for the study. All patients underwent TTE between 6 and 12 months after the PE episode. Since RIETE has no information available on CTEPH diagnosis, we considered patients not to have

@ERSpublications

The current predictive score, based on data during the index pulmonary embolism, is not sensitive enough in a chronic thromboembolic pulmonary hypertension (CTEPH) rule-out strategy http://ow.ly/8fGy30iIjgN

Cite this article as: Otero R, Bertoletti L, Muriel A, et al. Role of a clinical prediction score in a chronic thromboembolic pulmonary hypertension rule-out strategy. Eur Respir J 2018; 51: 1702576 [https://doi. org/10.1183/13993003.02576-2017]. 
CTEPH when a low probability of pulmonary hypertension was found on TTE, according to current guideline recommendations $[7,16]$ : systolic PAP levels $\leqslant 36 \mathrm{mmHg}$ or peak tricuspid regurgitation velocity $\leqslant 2.8 \mathrm{~m} \cdot \mathrm{s}^{-1}$ (or not measurable), and no additional TTE signs suggesting pulmonary hypertension (right ventricle/left ventricle basal diameter ratio $>1$, diastolic right ventricle diameter $>35 \mathrm{~mm}$, right ventricle hypokinesia, left ventricular eccentricity index $>1.0$ in systole and/or diastole and/or tricuspid annulus plane systolic excursion $<17 \mathrm{~mm}$ ).

The flow-chart of patients appears in figure 1. From 25695 PE patients included in the RIETE registry, we selected 2807 in whom a TTE was performed 6-12 months after acute PE. Finally, 2256 patients were analysed. CTEPH was ruled out by TTE in 1670 (74\%) patients, of whom 1295 were classified as "low-risk" by the clinical prediction score ( $\leqslant 6$ points). Among the remaining 586 patients with "likely" CTEPH on TTE, only 160 were classified as "high-risk" according to the score. In a "rule-out" strategy, using the score would help to avoid 1295 (57\%) unnecessary TTEs, but the proportion of false negatives was $72.7 \%$ (95\% CI $68.9-76.1 \%)$. In other words, the score would mistakenly suggest that TTE could be avoided in 426 (19\%) out of 2256 of patients.

The sensitivity of the score was $27.3 \%$ (95\% CI $23.7-30.9 \%)$ and the negative predictive value $75.2 \%$ (95\% CI 73.2-77.3\%). Others parameters, like specificity and positive predictive value are not relevant in this approach since the aim of this study was to validate the score in a rule-out strategy. Even if a higher threshold of $\leqslant 8$ points were applied this strategy would not be associated with a better sensitivity: $12.1 \%$ (95\% CI 9.4-14.7\%).

Early diagnosis of CTEPH remains challenging, with a considerable delay between symptoms onset and CTEPH diagnosis. The reported median time is $\sim 14$ months, even in experienced centres [17]. CTEPH is characterised by the classical "honeymoon": since patients may worsen after an initial improvement. An easily available score early after PE diagnosis may help clinicians to decide which patients would benefit from a more thorough screening for CTEPH.

The potential benefit of CTEPH screening at the time of PE diagnosis is controversial, but some authors have suggested this possibility to identify patients at high risk. In 2015, KLOK et al. [18] built CTEPH rule-out criteria based on a normal N-terminal pro-brain natriuretic peptide (NT-proBNP) level and the absence of three electrocardiographic characteristics in a prospective cohort of patients with PE undergoing TTE during follow-up. The presence of pulmonary hypertension was unlikely in $81 \%$ based on TTE criteria, with a sensitivity of $100 \%$ (95\% CI 56-100\%). The main limitations were that the validation was only possible in 134 patients and at 6 months. Interestingly, however, no clinical variables were included in the rule-out criteria, so some cases of "new onset" CTEPH could be previous to the acute PE episode.

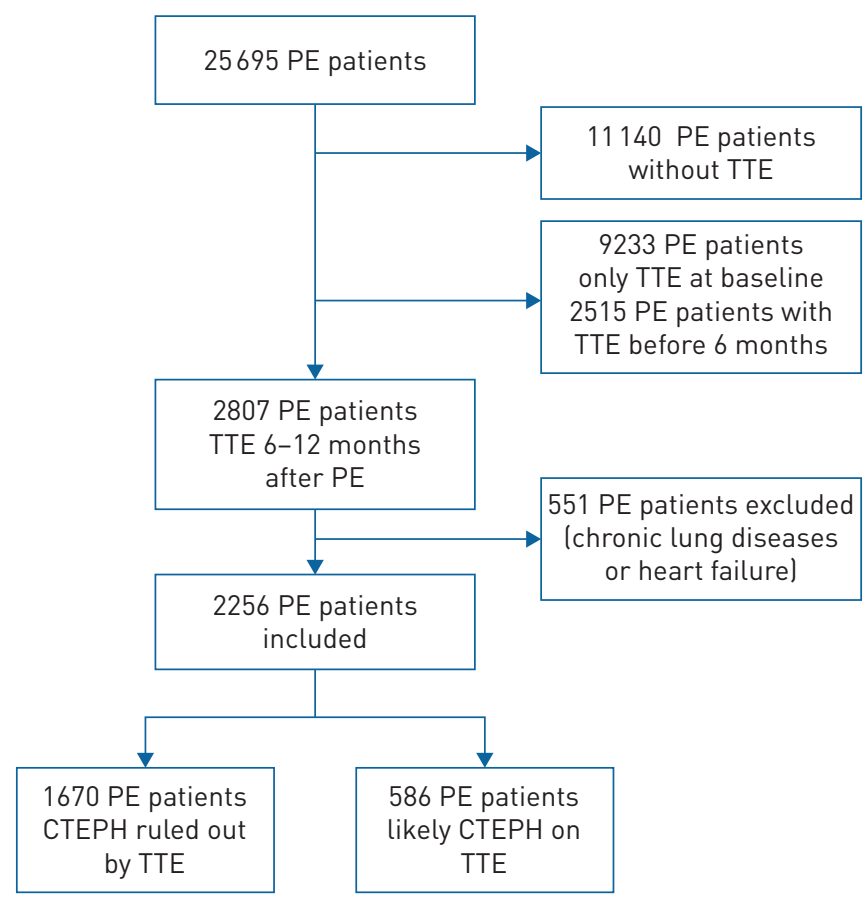

FIGURE 1 Flow chart of patients. PE: pulmonary embolism; TTE: transthoracic echocardiography; CTEPH: chronic thromboembolic pulmonary hypertension. 
Our findings do not confirm the sensitivity and negative predictive value of the score obtained during the derivation study [18]. The score may help us to avoid the up to $57 \%$ unnecessary TTEs, but with the risk of a substantial number of false negative results. One of the advantages of our approach is that it has been tested in a large sample of "real world" patients who underwent routine follow-up visits and one TTE between 6 and 12 months after PE.

Our approach has a number of limitations. First, even though TTE is still recommended as the initial noninvasive tool in the screening of $\mathrm{PH}$, it may frequently be inaccurate in estimating systolic PAP levels [19]. Second, the RIETE registry was not initially designed to identify PE patients at risk for CTEPH, and there is no information on a final confirmation of CTEPH in most of these patients. In addition, one of the variables in the model (symptom onset $>2$ weeks before PE diagnosis) is not available in RIETE. Thus, we replaced it with "isolated dyspnoea" at baseline and slightly modified the original score. Our main strengths are the large number of PE patients in the registry $(n=2256)$, and that the TTE criteria used for defining very unlikely CTEPH were based on current guideline recommendations [7].

Our results suggest that a predictive score based on data obtained during the index PE is not sensitive enough for a CTEPH rule-out strategy. With the aim of improving the diagnostic accuracy, other strategies should be evaluated, such as a combination of a predictive score based on the index PE and more specific biomarkers, for example NT-proBNP, during follow-up [18].

Remedios Otero $\oplus^{1}$, Laurent Bertoletti ${ }^{2}$, Alfonso Muriel $^{3}$, Carmine Siniscalchi ${ }^{4}$, Carmen Jimenez ${ }^{5,6}$, Jose Luis Lobo $^{7}$, Dana Kigitovica ${ }^{8}$, Roberto Quintavalla ${ }^{9}$, Anna Rocci ${ }^{10}$, Luis Jara-Palomares $\odot^{1}$ and Manuel Monreal ${ }^{11}$ for the RIETE Investigators ${ }^{12}$

${ }^{1}$ Medical Surgical Unit of Respiratory Diseases, Instituto de Biomedicina de Sevilla (IBiS), Centro de Investigación Biomédica en Red de Enfermedades Respiratorias (CIBERES), Hospital Universitario Virgen del Rocio, Seville, Spain. ${ }^{2}$ Service de Médecine Vasculaire et Thérapeutique, CHU de St-Etienne, INSERM, UMR1059, Université Jean-Monnet, INSERM, CIC-1408, Saint-Etienne, France. ${ }^{3}$ Clinical Biostatistics Unit, Hospital Ramón y Cajal, IRYCIS, CIBERESP, Dept of Nursing, Universidad de Alcalá, Madrid, Spain. ${ }^{4}$ Angiology Unit, Parma University Hospital, Parma, Italy. ${ }^{5}$ Cardiology Dept, Hospital Universitario 12 de Octubre, Madrid, Spain. ${ }^{6}$ Centro de Investigación Biomédica en Red de Enfermedades Cardiovasculares (CIBER-CV), Faculty of Medicine, Universidad Complutense de Madrid, Madrid, Spain. ${ }^{7}$ Respiratory Dept, Hospital Universitario Araba, Álava, Spain. ${ }^{8}$ Faculty of Continuing Education, Pauls Stradins Clinical University Hospital, Riga Stradins University, Riga, Latvia. ${ }^{9}$ Dept of Medicine 3, Azienda Ospedaliera Universitaria, Parma, Italy. ${ }^{10}$ Angiology Unit, Parma University Hospital, Parma, Italy. ${ }^{11}$ Dept of Internal Medicine, Hospital Universitari Germans Trias i Pujol, Badalona, Barcelona, Universidad Católica de Murcia, Spain. ${ }^{12} \mathrm{~A}$ full list of the RIETE Investigators can be found in the Acknowledgements section.

Correspondence: Remedios Otero, Medical Surgical Unit of Respiratory Diseases, Instituto de Biomedicina de Sevilla (IBiS), Centro de Investigación Biomédica en Red de Enfermedades Respiratorias (CIBERES), Hospital Universitario Virgen del Rocio, Seville, Spain. E-mail: rotero@separ.es

Received: Dec 112017 | Accepted after revision: Feb 102018

Conflict of interest: None declared.

Acknowledgements: We thank the RIETE Registry Coordinating Centre, S\&H Medical Science Service, for their quality control data, logistic and administrative support.

Coordinator of the RIETE registry: Manuel Monreal (Spain). RIETE steering committee members: Hervè Decousus (France), Paolo Prandoni (Italy) and Benjamin Brenner (Israel). RIETE registry coordinating centre: S\&H Medical Science Service.

Members of the RIETE group are as follows. Spain: Adarraga MD, Aibar MA, Aibar J, Alfonso M, Alonso A, Amado C, Arcelus JI, Ballaz A, Barba R, Barrón M, Barrón-Andrés B, Bascuñana J, Blanco-Molina A, Camon AM, Carrasco C, Cruz AJ, de Miguel J, del Toro J, Díaz-Pedroche MC, Díaz-Peromingo JA, Falgá C, Fernández-Capitán C, Fidalgo MA, Font C, Font L, Furest I, García MA, García-Bragado F, García-Morillo M, Gavín O, Gómez V, González-Martínez J, Grau E, Guijarro R, Gutiérrez J, Isern V, Jara-Palomares L, Jaras MJ, Jiménez D, Jiménez J, Jiménez R, Joya MD, Lalueza A, Lima J, Lobo JL, López-Jiménez L, López-Miguel P, López-Reyes R, López-Sáez JB, Lorente MA, Lorenzo A, Loring M, Lumbierres M, Madridano O, Marchena PJ, Monreal M, Morales MV, Muñoz N, Nieto JA, Nuñez A, Núñez MJ, Olivares MC, Otero R, Pedrajas JM, Pellejero G, Pérez-Ductor C, Peréz-Jacoiste A, Peris ML, Pesce ML, Porras JA, Riesco D, Rivas A, Rodríguez-Dávila MA, Rosa V, Rubio CM, Ruiz-Artacho P, Sahuquillo JC, Sala-Sainz MC, Sampériz A, Sancho T, Soler S, Soto MJ, Suriñach JM, Tolosa C, Torres MI, Trujillo-Santos J, Uresandi F, Usandizaga E, Valle R, Vela J, Vidal G and Villalobos A; Argentina: Gutiérrez P, Vázquez FJ and Vilaseca A; Belgium: Vanassche T, Vandenbriele C and Verhamme P; Czech Republic: Hirmerova J and Malý R; Ecuador: Salgado E; France: Benzidia I, Bertoletti L, Bura-Riviere A, Farge-Bancel D, Hij A, Merah A, Mahé I and Moustafa F; Israel: Bennidor R, Braester A, Brenner B, Ellis M and Tzoran I; Italy: Antonucci G, Bilora F, Bortoluzzi C, Brandolin B, Bucherini E, Cattabiani C, Ciammaichella M, Dentali F, Di Micco P, Duce R, Giorgi-Pierfranceschi M, Grandone E, Imbalzano E, Maida R, Mastroiacovo D, Ngoc V, Pace F, Parisi R, Pesavento R, Poggio R, Prandoni P, Quintavalla R, Rocci A, Siniscalchi C, Sotgiu P, Tufano A, Visonà A and Zalunardo B; Latvia: Skride A; Republic of Macedonia: Bosevski M and Zdraveska M; Switzerland: Bounameaux H and Mazzolai L; USA: Caprini J.

Support statement: We express our gratitude to Sanofi Spain for supporting this Registry with an unrestricted educational grant. We also express our gratitude to Bayer Pharma AG for supporting this Registry. Bayer Pharma AG's support was limited to the part of RIETE outside Spain, which accounts for a $24.70 \%$ of the total patients included in the RIETE Registry. 


\section{References}

1 Pengo V, Lensing AWA, Prins $\mathrm{MH}$, et al. Incidence of chronic thromboembolic pulmonary hypertension after pulmonary embolism. N Engl J Med 2004; 350: 2257-2264.

2 Becattini C, Agnelli G, Pesavento R, et al. Incidence of chronic thromboembolic pulmonary hypertension after a first episode of pulmonary embolism. Chest 2006; 130: 172-175.

3 Klok FA, van Kralingen KW, van Dijk APJ, et al. Prospective cardiopulmonary screening program to detect chronic thromboembolic pulmonary hypertension in patients after acute pulmonary embolism. Haematologica 2010; 95: 970-975.

4 Dentali F, Donadini M, Gianni M, et al. Incidence of chronic pulmonary hypertension in patients with previous pulmonary embolism. Thromb Res 2009; 124: 256-258.

5 Ribeiro A, Lindmarker P, Johnsson H, et al. Pulmonary embolism. Circulation 1999; 99: 1325-1330.

6 Ende-Verhaar YM, Cannegieter SC, Noordegraaf AV, et al. Incidence of chronic thromboembolic pulmonary hypertension after acute pulmonary embolism: a contemporary view of the published literature. Eur Respir J 2017; 49: 1601792 .

7 Galiè N, Humbert M, Vachiery J-L, et al. 2015 ESC/ERS Guidelines for the diagnosis and treatment of pulmonary hypertension. Eur Heart J 2016; 37: 67-119.

8 Escribano-Subías P, del Pozo R, Román-Broto A, et al. Management and outcomes in chronic thromboembolic pulmonary hypertension: from expert centers to a nationwide perspective. Int J Cardiol 2017; 203: 938-944.

9 Mayer E, Jenkins D, Lindner J, et al. Surgical management and outcome of patients with chronic thromboembolic pulmonary hypertension: results from an international prospective registry. J Thorac Cardiovasc Surg 2011; 141: 702-709.

10 Galiè N, Humbert M, Vachiery JL, et al. 2015 ESC/ERS Guidelines for the diagnosis and treatment of pulmonary hypertension. Eur Respir J 2015; 46: 903-975.

11 Coghlan JG, Denton CP, Grünig E, et al. Evidence-based detection of pulmonary arterial hypertension in systemic sclerosis: the DETECT study. Ann Rheum Dis 2014; 73: 1340-1349.

12 Giuliani L, Piccinino C, D’Armini MA, et al. Prevalence of undiagnosed chronic thromboembolic pulmonary hypertension after pulmonary embolism. Blood Coagul Fibrinolysis 2014; 25: 649-653.

13 Kayaalp I, Varol Y, Cimen P, et al. The incidence of chronic thromboembolic pulmonary hypertension secondary to acute pulmonary thromboembolism. Tuberk Toraks 2014; 62: 199-206.

14 Rubin LJ. Pulmonary hypertension: current management and future directions. In: Humbert M, Evgenov OV, Stasch J-P, eds. Pharmacotherapy of Pulmonary Hypertension. Berlin, Springer-Verlag, 2013; pp. 551-555.

15 Klok FA, Dzikowska-Diduch O, Kostrubiec M, et al. Derivation of a clinical prediction score for chronic thromboembolic pulmonary hypertension after acute pulmonary embolism. J Thromb Haemost 2016; 14: 121-128.

16 Lang RM, Badano LP, Mor-Avi V, et al. Recommendations for cardiac chamber quantification by echocardiography in adults: an update from the American society of echocardiography and the European association of cardiovascular imaging. Eur Heart J Cardiovasc Imaging 2015; 16: 233-271.

17 Pepke-Zaba J, Hoeper MM, Humbert M. Chronic thromboembolic pulmonary hypertension: advances from bench to patient management. Eur Respir J 2013; 41: 8-9.

18 Klok FA, Tesche C, Rappold L, et al. External validation of a simple non-invasive algorithm to rule out chronic thromboembolic pulmonary hypertension after acute pulmonary embolism. Thromb Res 2015; 135: 796-801.

19 Fisher MR, Forfia PR, Chamera E, et al. Accuracy of Doppler echocardiography in the hemodynamic assessment of pulmonary hypertension. Am J Respir Crit Care Med 2009; 179: 615-621. 